\title{
Acute Drug-Induced Cholestatic Syndrome in Basedow Graves' Disease
}

\author{
Robert Aurelian Tiucă, Alina Mioara Boeriu², Rareș Adrian Georgescu³ , Ionela Maria Pașcanu \\ 1 Clinic of Endocrinology, County Clinical Hospital Mureș, Târgu Mureș, Romania \\ 2 Department of Gastroenterology, County Clinical Hospital Mureș, "George Emil Palade” University of Medicine and Pharmacy, \\ Science and Technology, Târgu Mureș, Romania \\ 3 Department of Surgery, County Clinical Hospital Mureș, "George Emil Palade" University of Medicine and Pharmacy, Science and \\ Technology, Târgu Mureș, Romania \\ 4 Department of Endocrinology, County Clinical Hospital Mureș, "George Emil Palade" University of Medicine and Pharmacy, Science \\ and Technology, Târgu Mureș, Romania
}

\section{CORRESPONDENCE}

\section{Alina Mioara Boeriu}

Department of Gastroenterology,

County Clinical Hospital Mureș

Str. Gheorghe Marinescu nr. 1

540103 Târgu Mureș, Romania

Tel +40265215 133

E-mail: aboeriu@gmail.com

\section{ARTICLE HISTORY}

Received: March 14, 2020

Accepted: May 15, 2020
Robert Aurelian Tiucă • Str. Gheorghe Marinescu nr 38, 540139 Târgu Mures, Romania. Tel: +40 265217 274, E-mail: tiuca.robert@gmail.com

Rareș Adrian Georgescu • Str. Gheorghe Marinescu nr. 1, 540103 Târgu Mureș, Romania. Tel: +40 265215 133, E-mail: rares1geo@yahoo.com

Ionela Maria Pașcanu • Str. Gheorghe Marinescu nr. 38, 540139 Târgu Mureș, Romania. Tel: +40 265217 274, E-mail: iopascanu@gmail.com

\begin{abstract}
Introduction: Graves' disease (GD), an autoimmune disorder caused by high levels of autoantibodies against the thyroid-stimulating hormone receptor, is considered the most common cause of thyrotoxicosis, characterized by features such as goiter, ophthalmopathy and dermopathy. In our country, the administration of antithyroid drugs (ATD) is the first line of treatment in this disease. Side effects are rare but some of them, such as agranulocytosis or liver damage, may become serious. Case presentation: We report the case of a 20 -year-old female patient who was diagnosed with GD after being previously diagnosed with viral hepatitis A. Treatment was initiated with methimazole $30 \mathrm{mg} / \mathrm{day}$, and three weeks later she developed intense hepatic cytolysis and cholestatic syndrome, therefore the ATD was stopped. A suspicion of autoimmune liver disease was raised, and a liver biopsy was performed in order to establish the diagnosis. The next therapeutic option for hyperthyroidism was radioactive iodine (RAl). Three months following RAl, the patient presented severe hypothyroidism, thereupon treatment with levothyroxine was initiated. Conclusions: Although severe acute liver injury is rare, mild liver dysfunction is quite common in patients with GD. The overproduction of thyroid hormones, or the treatment with ATD through immune mediated processes or drug reactions, represent possible mechanisms responsible for liver damage.
\end{abstract}

Keywords: Graves' disease, methimazole, hepatitis, cytolysis, cholestatic syndrome

\section{INTRODUCTION}

Graves' disease (GD) is an organ-specific autoimmune disorder of unknown cause and the most common form of thyrotoxicosis. It affects women more commonly than men $(5: 1)$, with a peak incidence between the second and forth decade of life.1,2 Thyrotoxicosis, goiter, ophthalmopathy, and dermopathy are features that can be typically found in a patient with GD. ${ }^{1}$ Goiter and hyperthyroidism that appear in GD are due to a high level of circulating autoan- 
tibodies that are directed against the thyroid-stimulating hormone (TSH) receptor in the thyroid cell membrane (TRAb). ${ }^{1}$ These autoantibodies are synthesized by B lymphocytes in the thyroid gland, which were stimulated by the $\mathrm{T}$ lymphocytes. ${ }^{1,2} \mathrm{~A}$ thyroid ultrasound usually describes a diffusely enlarged, hypoechoic thyroid with increased vascularity. ${ }^{2}$ There is evidence that suggests a familial predisposition in developing GD, and environmental triggers include stress, tobacco use, pregnancy, viral or bacterial infections, and iodine exposure. ${ }^{1}$ Treatment for GD implies the use of antithyroid drugs (ATDs) such as methimazole, carbimazole, or propylthiouracil in order to reduce the high production of thyroid hormones. ${ }^{1,2}$ Common side effects of ATDs are itching, skin rash, and abnormal hair loss, while less common side effects include muscle and joint pain, headache, swelling, and in severe cases liver injury or agranulocytosis. ${ }^{2}$ Another treatment option for GD, which reduces the amount of thyroid tissue, is radioactive iodine treatment (RAI) or total thyroidectomy. ${ }^{1,2}$ This article aims to present the case of a young female patient with GD who had been previously diagnosed with viral hepatitis A and who developed acute cholestatic syndrome after ATD use.

\section{CASE PRESENTATION}

A 20-year-old female patient was admitted to the Infectious Diseases Department of Mureș Clinical County Hospital with symptoms such as nausea, vomiting, jaundice, and urinary hyperchromia. The laboratory workup revealed high values of direct bilirubin and total bilirubin, hepatic cytolysis, and positive immunoglobulin $\mathrm{M}$ antibody to hepatitis A virus. Abdominal ultrasound showed hepatosplenomegaly, visible intrahepatic ducts, and gallbladder wall thickening. A diagnosis of acute viral hepatitis A was established and treatment with intravenous infusions of glucose 5\% and hepatoprotective agents was initiated. The patient's general status as well as the hepatic panel tests improved. During hospitalization, she presented an enlargement of the anterior cervical region, therefore, two weeks after discharge, she was evaluated by an endocrinologist.

A thyroid ultrasound was performed, which described an increased volume, with inhomogeneous structure and enhanced vascularity, suggesting an autoimmune thyroid disease. Blood test evaluation showed thyrotoxicosis with a TSH of $0.0090 \mu \mathrm{UI} / \mathrm{mL}$ (normal range: $0.55-4.78$ ),

TABLE 1. The evolution of liver panel, bilirubin tests, and thyroid function

\begin{tabular}{|c|c|c|c|c|c|c|c|}
\hline Time frame & $\begin{array}{c}\text { AST } \\
(N R: 5-34 \cup / L)\end{array}$ & $\begin{array}{c}\text { ALT } \\
\text { (NR: } 0-55 \mathrm{U} / \mathrm{L})\end{array}$ & $\begin{array}{c}\text { GGT } \\
(\mathrm{NR}: 12-64 \mathrm{U} / \mathrm{L})\end{array}$ & $\begin{array}{c}\text { DB } \\
\text { (NR: } 0.0-0.5 \mathrm{mg} / \mathrm{dL})\end{array}$ & $\begin{array}{c}\text { TB } \\
\text { (NR: } 0.2-1.2 \mathrm{mg} / \mathrm{dL})\end{array}$ & $\begin{array}{l}\text { Thyroid } \\
\text { function }\end{array}$ & Treatment received \\
\hline $\begin{array}{l}\text { Onset of the viral } \\
\text { hepatitis }\end{array}$ & 1516 & 1727 & - & 5.22 & 6.28 & - & $\begin{array}{c}\text { Hepatoprotective drugs } \\
+ \\
\text { infusions with glucose } \\
5 \%\end{array}$ \\
\hline $\begin{array}{l}2 \text { weeks after being } \\
\text { discharged from the } \\
\text { Infectious Diseases } \\
\text { Department }\end{array}$ & 80 & 150 & - & 0.97 & 1.44 & Thyrotoxicosis & $\begin{array}{c}\text { Hepatoprotective drugs } \\
+ \\
\text { introduction of ATD }\end{array}$ \\
\hline 3 weeks later & 1393 & 1995 & 275 & 8.98 & 12.39 & - & \multirow{3}{*}{$\begin{array}{c}\text { Stopping methimazole } \\
\text { Hepatoprotective drugs } \\
+ \\
\text { prednisone } \\
+ \\
\text { gastroprotective agents } \\
+ \\
\text { cardioactive agents }\end{array}$} \\
\hline $\begin{array}{l}\text { After } 10 \text { days of } \\
\text { treatment }\end{array}$ & 259 & 628 & 238 & 5.24 & 6.44 & - & \\
\hline $\begin{array}{l}\text { After } 1 \text { month from } \\
\text { stopping ATD }\end{array}$ & 46 & 166 & 97 & 1.36 & 2.22 & Euthyroidism & \\
\hline 5 months later & 25 & 38 & 28 & - & - & $\begin{array}{l}\text { Relapse of the } \\
\text { hyperthyroidism }\end{array}$ & $\begin{array}{c}\text { Hepatoprotective drugs } \\
+ \\
\text { cardioactive agents }\end{array}$ \\
\hline 2 months later & 34 & 60 & 36 & 0.44 & 1.1 & $\begin{array}{l}\text { Mild } \\
\text { thyrotoxicosis }\end{array}$ & $\begin{array}{c}3 \text { weeks after RAl } \\
\text { Hepatoprotective drugs } \\
+ \\
\text { cardioactive agents }\end{array}$ \\
\hline 3 months later & 23 & 30 & 21 & - & - & $\begin{array}{c}\text { Severe } \\
\text { hypothyroidism }\end{array}$ & Levothyroxine \\
\hline
\end{tabular}


free thyroxine (FT4): $4.33 \mathrm{ng} / \mathrm{dL}$ (normal range: 0.89 1.76), free triiodothyronine (FT3): $14.68 \mathrm{pg} / \mathrm{mL}$ (normal range: $2.3-4.2$ ), with high levels of anti-thyroid peroxidase (ATPO) of 1,571.0 UI/mL (normal range: <35) and TRAb: $33.41 \mathrm{UI} / \mathrm{L}(<1.75)$. She was eventually diagnosed with GD and treatment with $30 \mathrm{mg}$ of methimazole along with $30 \mathrm{mg}$ of propranolol was started.

After roughly three weeks of treatment with ATDs, the patient was admitted to the Endocrinology Department of Mureș County Clinical Hospital complaining of tiredness, fatigue, jaundice, and urinary hyperchromia. Physical examination revealed icteric sclera and skin, no signs of ascites or abdominal tenderness, negative Murphy's sign, and no ophthalmopathy. The liver blood panel described hepatic cytolysis and cholestatic syndrome on several determinations (Table 1 ).

While the patient was admitted to our department, treatment with hepatoprotective drugs was started, whereas the treatment with ATDs was stopped. However, the patient's general state did not improve. A suspicion of autoimmune cholangiohepatitis was raised, and the patient was transferred to the Gastroenterology Department for further medical investigations.

In the Gastroenterology Department, the physical examination revealed hepatosplenomegaly, normal heart rate and blood pressure. Liver tests showed severe cytolysis and cholestasis. Hepatitis B and C testing, and the markers for autoimmune hepatitis and primary biliary cirrhosis (anti-smooth muscle antibodies, anti-liver kidney microsomal type 1 antibodies, antimitochondrial antibodies, antinuclear antibodies, anti-soluble liver antigen antibodies) were negative, with normal serum protein electrophoresis, prothrombin time, and albumin levels. Abdominal ultrasound depicted splenomegaly, lymphadenopathy in the hepatic hilum, hepatomegaly, and gallbladder wall thickening, with no obstruction of biliary ducts. Infusions with hepatoprotective agents were initiated, as well as treatment with prednisone $(1 \mathrm{mg} / \mathrm{kg} /$ day $)$ and ursodeoxycholic acid ( $10 \mathrm{mg} / \mathrm{kg} /$ day $)$.

Liver biopsy described hepatitis with minimum necrotic-inflammatory activity, and minimum inflammatory infiltrate at the portal space formed by lymphocytes, neutrophils, and eosinophilic granulocytes (Figure 1).

Under treatment with hepatoprotective, gastroprotective, and cardioactive agents, prednisone tapering regimen and ursodeoxycholic acid, the patient's liver condition progressively improved. She was retransferred to the Endocrinology Department, where the thyroid function tests were normal, while the hepatic panel described mild cytolysis and cholestatic syndrome (Table 1).
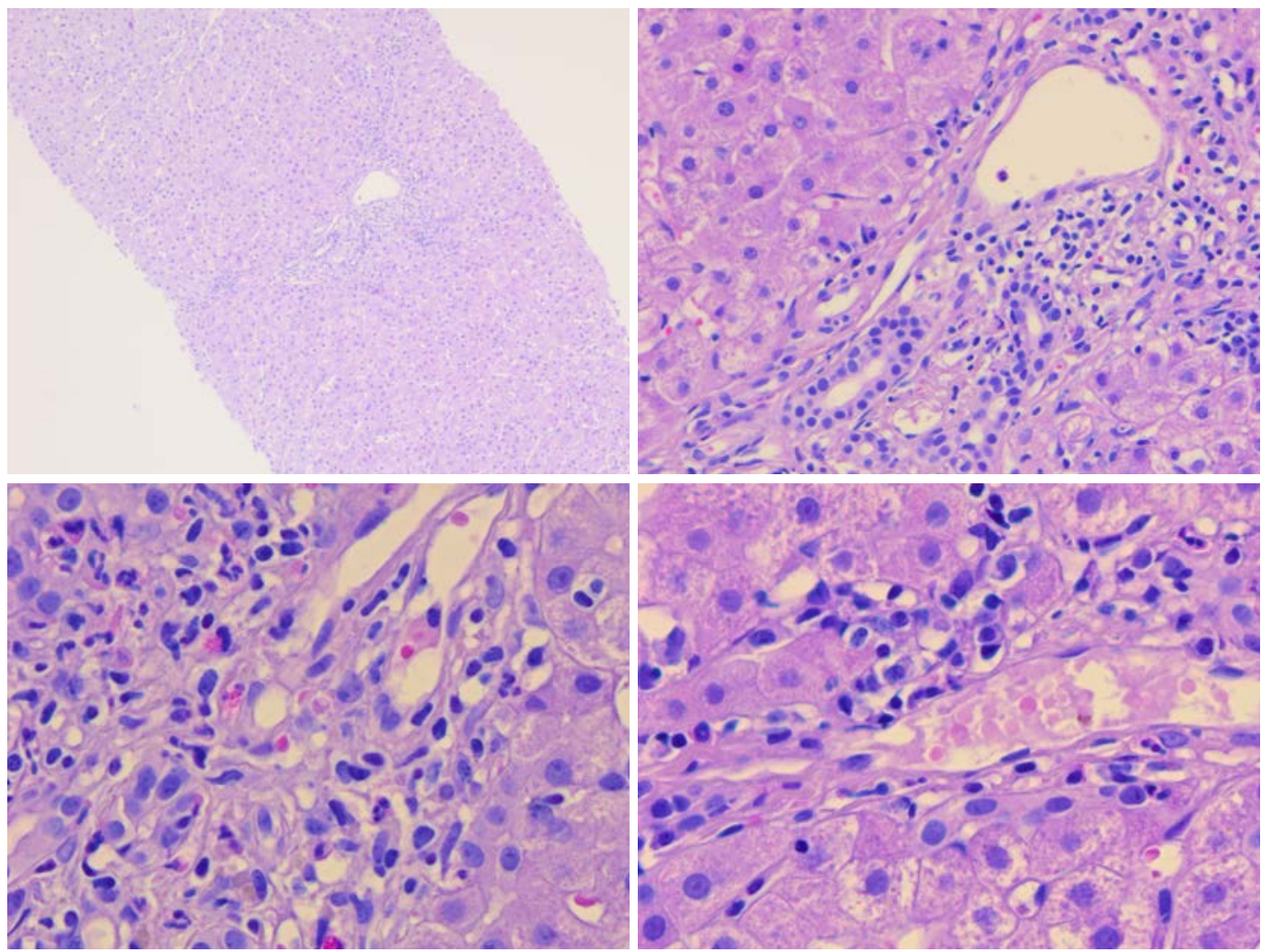

FIGURE 1. The microscopic aspect of the liver biopsy 
The patient was reevaluated after five months, when the thyroid function tests revealed a relapse of the hyperthyroidism, whereas the liver function tests were normal. Given the medical history of the patient and the acute liver injury (ALI) secondary to the administration of ATDs, the patient was advised to undergo treatment with RAI. One month later, she received a therapeutic dose of $11.72 \mathrm{mCi}$ of I-131. The patient was reevaluated three weeks later, when she was still in mild thyrotoxicosis, eventually being discharged without any additional ATD. Three months later, the patient presented severe hypothyroidism (TSH level of $285.746 \mu \mathrm{UI} / \mathrm{mL}$ and FT3 level of $<0.20 \mathrm{pg} / \mathrm{mL}$ ), with a low thyroid volume and normal liver functions tests, thereupon treatment with levothyroxine was initiated (Table 1).

The patient agreed to the publication of her medical information, the manuscript being written respecting the ethical principles stated in the Declaration of Helsinki.

\section{DISCUSSIONS}

We report the case of a 20-year-old female patient who was diagnosed with GD. Prior to the diagnosis, the patient had viral hepatitis $\mathrm{A}$, which required the admission to the Infectious Diseases Department. ATDs are usually the firstline treatment option with remission rates ranging from $14 \%$ to $80 \%$, the recommended duration of therapy being 12-18 months. ${ }^{2,3}$ In our case, the treatment was started with methimazole $30 \mathrm{mg} /$ day alongside with propranolol $30 \mathrm{mg} /$ day. Our patient had slightly elevated liver function tests before initiating the ATD, most probably due to thyrotoxicosis; nevertheless, three weeks after starting the medication, she developed jaundice, urinary hyperchromia, and fatigue, suggesting an ALI.

The incidence of hepatotoxicity associated with the use of any ATD is low $(<0.5 \%)$, propylthiouracil being the thionamide that is reported to have a higher risk of serious, non-dose related liver injury, especially in pediatric patients. The risk of liver failure is 1 in 2,000 children and 1 in 10,000 adults. ${ }^{4,5}$ On the other hand, methimazole toxicity is found more often in patients over 40 years of age, with no reported deaths from liver failure. ${ }^{4}$ In the literature, there are several studies that have observed the hepatotoxicity profiles of methimazole vs. propylthiouracil. A study conducted in Japan found a $6.6 \%$ incidence of methimazole-induced hepatotoxicity from $30 \mathrm{mg}$ /day compared to $26.9 \%$ in case of propylthiouracil at $300 \mathrm{mg} /$ day. $^{4,6}$ Wang et al. reported that hepatitis had a higher incidence rate than acute liver failure (ALF) when comparing methimazole vs. propylthiouracil. 7 Moreover, methimazole use, especially in high dose, associated an increased risk of hepatitis when compared with any propylthiouracil use. ${ }^{7}$ Rivkees \& Szarfman reported that methimazole had a higher rate of mild liver injury (cytolysis, jaundice, or cholestasis) but a lower rate of severe liver injury (hepatitis, ALF, or liver transplant) than propylthiouracil. ${ }^{8}$

A first hypothesis in the mechanism of developing an ALI in patients with GD is that hyperthyroidism can cause liver damage directly by increasing the metabolic rate, resulting in a higher oxidative capacity and oxidative tissue damage. ${ }^{1}$ Oshima et al. reported in 1990 an autopsy case of death due to hyperthyroidism in which the autopsy revealed hepatic inflammation, fibrosis, and centrilobular necrosis. ${ }^{9-11}$ Hyperthyroidism increases the production of insulin-like growth factor within the liver, resulting in a hypermetabolic state that can make the liver more prone to injury. ${ }^{12}$

A second hypothesis in developing an ALI after starting treatment with methimazole could be related to the implication of an immune-mediated process and/or drug reactions, though the exact mechanism is not yet fully understood. ${ }^{4}$ In 2004, Mikhail reported a case of a 43-year-old woman who developed severe, though reversible cholestatic jaundice after 4 weeks of treatment with methimazole, with an improvement in general state after stopping the medication. ${ }^{13}$ Drug-induced liver injury due to methimazole is reported more often in the first weeks after starting the treatment, the injury having usually a cholestatic type pattern with symptoms such as jaundice, fatigue, pruritus, and malaise. ${ }^{4,13-15}$ Chang et al. reported that elevated TRAb levels might predispose the patient to carbimazole/ methimazole-induced cutaneous reactions and/or hepatotoxicity. ${ }^{16}$ Heidari et al. found that mice that were treated with a nonhepatotoxic dose of bacterial lipopolysaccharide (LPS) from E. coli as well as with ATD in nonhepatotoxic doses, presented with hepatic inflammation that eventually led to ALI. ${ }^{17}$ LPS can stimulate toll-like receptors and activate the Kupffer cells that could damage the hepatocytes and furthermore, produce inflammatory cytokines and proteolytic enzymes. ${ }^{17}$ After the inhibition of Kupffer cells by methyl palmitate, methimazole-induced hepatotoxicity as well as propylthiouracil-induced liver injury in LPS-treated mice diminished. ${ }^{17}$

A third hypothesis for the onset of an ALI is the presence of an underlying autoimmune disease that causes serious damage to the liver such as an autoimmune hepatitis. In order to diagnose an autoimmune liver disease, autoimmune markers and liver biopsy are needed..$^{10}$ In our case, biopsy found no specific microscopic features for autoimmune hepatitis, and serum tests were negative.

In our case, the most plausible hypothesis for the occurrence of ALI is that the recent history of viral hepatitis 
A, concurrent with the consecutive administration of methimazole, led to the development of an acute cholestatic syndrome.

Another treatment option for hyperthyroidism is based on reduction of the amount of thyroid tissue with either RAI or thyroidectomy, especially in patients with relapsing hyperthyroidism after stopping the ATD. ${ }^{2} \mathrm{RAI}$ for GD is a safe form of treatment, though with a latency period that can last up to 6 months. ${ }^{3}$ Sundaresh $e t$ al. conducted a retrospective study on 720 patients and reported a failure rate in correcting the hyperthyroidism of $48.3 \%$ for ATD treatment compared with $8 \%$ for RAI. ${ }^{18}$ Nearly 3 months after RAI, our patient developed severe hypothyroidism, and treatment with levothyroxine was initiated.

\section{CONCLUSIONS}

Although severe ALI is rare, mild liver dysfunction is quite common in patients with GD. Overproduction of thyroid hormones, or treatment with ATD through immunemediated processes or drug reactions represent possible mechanisms responsible for liver damage. Liver tests monitoring during ATD therapy is recommended, especially in patients with prior liver dysfunction. In cases where ATDs are not indicated, definitive treatment with either RAI or total thyroidectomy may represent effective therapeutic options. Although hypothyroidism is a complication of the definitive treatment, management of this condition may be easier than the one of hyperthyreosis.

\section{CONFLICT OF INTEREST}

Nothing to declare.

\section{ACKNOWLEDGEMENT}

We acknowledge the cooperation of Prof. Dr. Ovidiu Simion Cotoi and Dr. Mihaela Sincu for performing the pathological evaluation, which played an important role in elucidating the final diagnosis.

\section{REFERENCES}

1. Cooper D, Landenson P. The thyroid gland. In: Gardner D, Shoback D, ed. Greenspan's Basic \& Clinical Endocrinology. 10th ed. McGraw-Hill Education, 2017; p. 171-239.

2. Kahaly G, Bartalena L, Hegedüs L, Leenhardt L, Poppe K, Pearce S. 2018 European Thyroid Association Guideline for the Management of Graves' Hyperthyroidism. Eur Thyroid J. 2018;7:167-186.

3. Cipolla C, Graceffa G, Calamia S, et al. The value of total thyroidectomy as the definitive treatment for Graves' disease: A single centre experience of 594 cases. J Clin Trans/ Endocrinol. 2019;16:100-183.

4. Akmal A, Kung J. Propylthiouracil, and methimazole, and carbimazolerelated hepatotoxicity. Expert Opin Drug Saf. 2014;13:1397-1406.

5. Karras S, Memi E, Kintiraki E, Krassas G. Pathogenesis of propylthiouracilrelated hepatotoxicity in children: present concepts. J Pediatr Endocrino Metab. 2012:25:623-630.

6. Nakamura H, Noh J, Itoh K, Fukata S, Miyauchi A, Hamada N. Comparison of Methimazole and Propylthiouracil in Patients with Hyperthyroidism Caused by Graves' Disease. J Clin Endocrinol Metab. 2007;92:2157-2162.

7. Wang $\mathrm{M}$, Lee $\mathrm{W}$, Huang $\mathrm{T}$, Chu C, Hsieh C. Antithyroid drug-related hepatotoxicity in hyperthyroidism patients: a population-based cohort study. Br J Clin Pharmacol. 2014;78:619-629.

8. Rivkees S, Szarfman A. Dissimilar Hepatotoxicity Profiles of Propylthiouracil and Methimazole in Children. J Clin Endocrinol Metab. 2010;95:32603267.

9. Oshima T, Maeda H, Takayashu T, et al. An autopsy case of sudden death due to hyperthyroidism. Nihon Hoigaku Zasshi. 1990;44:365-370.

10. Heidari R, Niknahad H, Jamshidzadeh A, Eghbal M, Abdoli N. An Overview on the Proposed Mechanisms of Antithyroid Drugs-Induced Liver Injury Adv Pharm Bull. 2015;5:1-11

11. Chen W, Zhu Z, Wang C, Chien M. Cholestasis and Acute Cholecystitis in Hyperthyroidism Treated With Methimazole. Int J Gerontol. 2009;3:248250

12. Tseng F, Chen Y, Chi Y, Chen P, Yang W. Serum levels of insulin-like growth factor 1 are negatively associated with log transformation of thyroidstimulating hormone in Graves' disease patients with hyperthyroidism or subjects with euthyroidism. Medicine (Baltimore). 2019;98:e14862.

13. Mikhail N. Methimazole-induced Cholestatic Jaundice. South Med J. 2004;97:178-182

14. Li X, Jin S, Fan Y, et al. Association of HLA-C*03:02 with methimazoleinduced liver injury in Graves' disease patients. Biomed Pharmacother. 2019;117:109095

15. Cooper D. Antithyroid Drugs. N Engl J Med. 2005;352:905-917.

16. Chang L, Chang $C$, Chen $P$, et al. Thyrotropin receptor antibodies and a genetic hint in antithyroid drug-induced adverse drug reactions. Expert Opin Drug Saf. 2018;17:775-784

17. Heidari R, Ahmadi F, Rahimi H, et al. Exacerbated liver injury of antithyroid drugs in endotoxin-treated mice. Drug Chem Toxicol. 2018;42:615-623.

18. Sundaresh V, Brito J, Thapa P, Bahn R, Stan M. Comparative Effectiveness of Treatment Choices for Graves' Hyperthyroidism: A Historical Cohort Study. Thyroid. 2017;27:497-505 